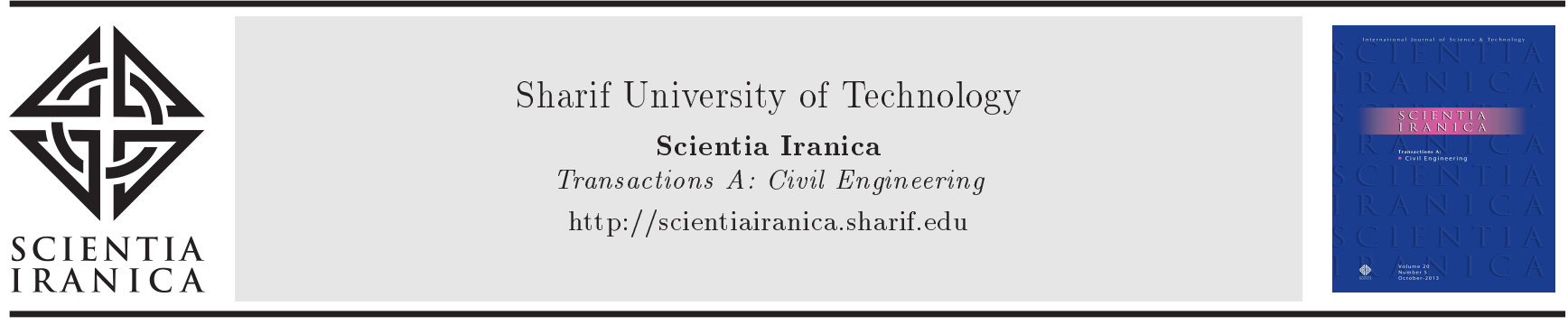

\title{
Uncoupled analysis of Rc-slabs under near-field air explosions: Examination of various empirical equations for simulating blast loads
}

\author{
A. Rasouli and H. Toopchi-Nezhad* \\ Department of Civil Engineering, Razi University, Kermanshah, 67149-67346, Iran. \\ Received 5 October 2016; received in revised form 24 June 2017; accepted 4 December 2017
}

KEYWORDS
Air detonation;
Near-field explosion;
Uncoupled blast
analysis;
Reinforced concrete
slab;
Empirical blast loads.

\section{Introduction}

An explosive incident may result from a variety of events including industrial accidents or terrorist bomb attacks. Traditionally, the vast majority of civilian research studies in the field of blast protection have been focused on the accidental explosion of specific facilities such as chemical storage tanks located in industrial plants [1]. The worldwide growing threat of terrorism and the fact that most of terrorist attacks involve the use of explosive devices have extended

\footnotetext{
*. Corresponding author. Telefax: +988334283264 . E-mail addresses: h.toopchinezhad@razi.ac.ir and toopchi@gmail.com (H. Toopchi-Nezhad).
}

\begin{abstract}
In an uncoupled analysis, blast loads can be evaluated by empirical models variety of empirical models. However, the potentials of these models may not be fully realized due to high variations that may exist in their outcomes, particularly at detonations close standoff distance from the target. As such, the selection of an ppropriate model should be made with special considerations. This paper investigates the efficiency of various empirical models in blast analysis of the RC-slabs that are subjected to in a set of nonlinear FEA runs. Due to the proximity of detonations, the distribution of blast-overpressure across the concrete slab at any instant of time is nonuniform. A simplified in this study. To examine the effectiveness of the empirical models, the FEA-results are compared with the observations made in a set of previous experimental studies. Based on made on the performance of the other models.
\end{abstract}

(C) 2019 Sharif University of Technology. All rights reserved. the scope of research studies from specific industrial facilities to many other civil structures. Accordingly, the dynamic response simulation of structures to air blast loads has been a subject of extensive research studies over the past decades [2-7].

The effective blast analysis and design of structures requires a thorough understanding of blast wave propagation and the dynamic response of various structural elements. As a cost-effective analysis approach, the calculation of blast wave propagation effects may be separated from the evaluation of structural response (such analysis is named "uncoupled"). Therefore, blast loads resulting from the detonation of an explosive of specific mass located at a particular standoff distance from the structure can be evaluated with the aid of empirical models. These loads may be applied to the structure in a separate response analysis $[8,9]$. 
The main objective of this paper is to investigate the accuracy of various empirical models that are available in the literature to evaluate the blast load effects on structures. The study is focused on the near-field explosions. In a near-field explosion, the distribution of blast overpressure on the surface of structure will be highly nonuniform [8]. A simplified approach has been developed in this study to account for the nonuniform distribution of blast overpressure across the surface of structure. In order to examine the accuracy of various empirical models and the effectiveness of the proposed simplified approach, finite-element analysis results of a set of reinforced concrete slabs under the effect of various explosions are compared with the results of previous experimental studies.

The components of this paper include a brief review of the characteristics of blast waves, a literature review of various empirical models that predict both the peak magnitude and time duration of blast overpressure phase, results of a set of previous experimental studies on reinforced concrete slab specimens (these results are utilized to examine the accuracy of the empirical models), a detailed description of the simplified approach developed in this study to account for nonuniform distribution of blast overpressure across the concrete slabs, finite-element modeling of slab specimens, mesh- and area-segment sensitivity analysis studies, a detailed comparison of the finite-element analysis and experimental studies, and concluding remarks together with a summary of the paper.

\section{Characteristics of blast waves}

Figure 1 shows a typical pressure-time profile of a blast wave that comprises an overpressure phase followed by an under-pressure phase [9]. Detonation of a high explosive material produces a compressed high temperature gas expanding supersonically outward from

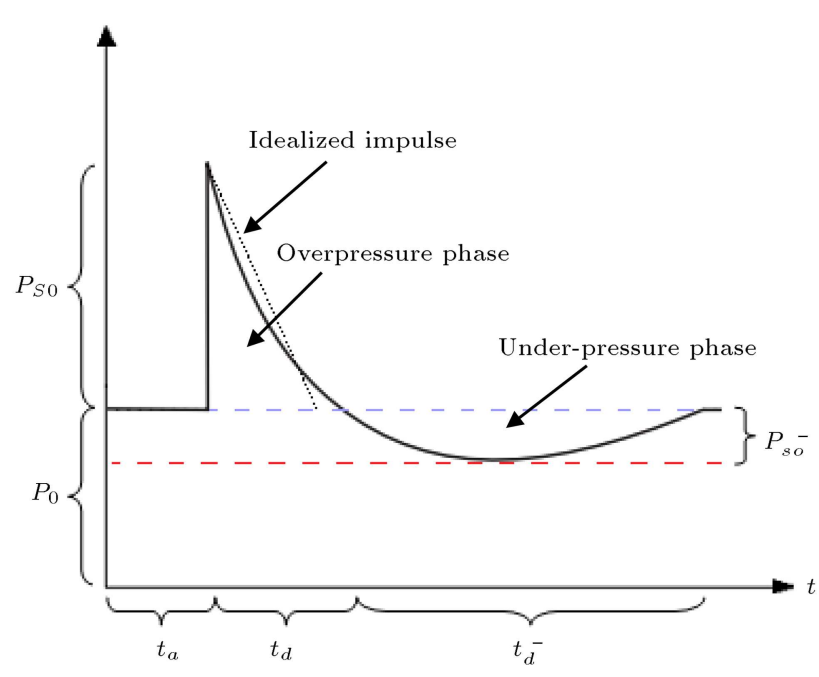

Figure 1. Typical pressure-time profile of a blast wave. the explosive core. The expansion of compressed gas influences the surrounding air by forming a layer of compressed air in front of the gas (blast wave). As seen in Figure 1, upon detonation, at an arrival time of $t_{a}$, the blast wave pressure violently increases from ambient pressure, $P_{0}$, to a peak overpressure, $P_{\text {so }}$. Over the time duration of $t_{d}$, the peak overpressure drops back to the ambient pressure and, then, reaches a peak under-pressure $P_{s o}^{-}$due to a rapid decrease in the pressure of the expanding gas. The under-pressure physically tends to suck items back in towards the core of expansion. Eventually, over the time duration of $t_{d}^{-}$, the under-pressure rises back to the ambient pressure and the situation returns to an equilibrium. It should be noted that, at any instant of time, the magnitude of the overpressure at any point in the space depends on distance $R$ of that point to the center of the explosive material (charge) and the charge weight, $W$ (typically specified as an equivalent mass of TNT). To account for these parameters, the overpressure is specified as a scaled distance, defined [9] as $Z=R / W^{1 / 3}$.

For many practical applications, a triangular pulse may simplify the overpressure phase of the profile shown in Figure 1. Additionally, it is a common practice to neglect the under-pressure phase of the profile, particularly in the blast response analysis of relatively rigid structures [8].

As seen in Figure 1, due to a rapid exponential decay in the peak overpressure, the variation of pressure with time is nonlinear. There are several imperial equations, including Flynn [10], Brode [11], Ethridge [12], and Dewey [13], to simulate the overpressure as a function of time. This paper employs a modified version of the original equation developed by Friedlander [14] as a commonly adopted equation to simulate the blast wave overpressure. A modified version of Friedlander equation that accounts for ambient pressure, $P_{0}$, is read as follows [15]:

$$
P(t)=P_{0}+P_{s o}\left(1-\frac{t}{t_{d}}\right) e^{-b \frac{t}{t_{d}}}
$$

where $b$ is a wave-decay parameter given by Eq. (2) in terms of scaled distance $Z$ [16]. The rest of parameters used in Eq. (1) are defined in Figure 1. It should be noted that the origin of $t$ in Eq. (1) is set to the arrival of the peak overpressure, namely $t_{a}$.

$$
\begin{aligned}
b= & 0.3306 Z^{4}-3.1838 Z^{3}+11.755 Z^{2}-20.308 Z \\
& +15.12 \text { for } Z<3 \mathrm{~m} / \mathrm{kg}^{1 / 3} .
\end{aligned}
$$

When encountering a perpendicular obstacle such as a rigid wall, the moving air molecules in front of a blast wave are brought to rest and further compressed. This produces a reflected overpressure, $P_{r}(t)$, on the surface of the wall that will be, in turn, of higher magnitude 
Table 1. Empirical models for peak overpressure, $P_{s o}$.

\begin{tabular}{|c|c|c|}
\hline Model & Peak overpressure, $P_{s o}(\mathrm{kPa})$ & Considerations \\
\hline Brode [11] & $\begin{array}{c}98.07\left(\frac{6.7}{Z^{3}}+1\right) \\
98.07\left(\frac{0.975}{Z}+\frac{1.455}{Z^{2}}+\frac{5.85}{Z^{3}}-0.019\right)\end{array}$ & $\begin{array}{c}(Z<0.906) \\
(0.93<Z<9.8)\end{array}$ \\
\hline $\begin{array}{l}\text { Newmark \& } \\
\text { Hansen }[18]\end{array}$ & $98.07\left(\frac{6784}{Z^{3}}+\frac{93}{Z^{3 / 2}}\right)$ & - \\
\hline Baker [15] & $\begin{array}{l}98.07\left(\frac{20.06}{Z}+\frac{1.94}{Z^{2}}-\frac{0.04}{Z^{3}}\right) \\
98.07\left(\frac{0.67}{Z}+\frac{3.01}{Z^{2}}+\frac{4.31}{Z^{3}}\right)\end{array}$ & $\begin{array}{l}(0.05<Z<0.5) \\
(0.5<Z<70.9)\end{array}$ \\
\hline Henrych [19] & $\begin{array}{c}98.07\left(\frac{14.072}{Z}+\frac{5.54}{Z^{2}}-\frac{0.357}{Z^{3}}+\frac{0.00625}{Z^{4}}\right) \\
98.07\left(\frac{6.194}{Z}-\frac{0.326}{Z^{2}}+\frac{2.132}{Z^{3}}\right) \\
98.07\left(\frac{0.662}{Z}+\frac{4.05}{Z^{2}}+\frac{3.228}{Z^{3}}\right)\end{array}$ & $\begin{array}{l}(0.05<Z<0.3) \\
(0.3<Z<1.0) \\
(1.0<Z<10.0)\end{array}$ \\
\hline Held [20] & $\left(\frac{2}{Z^{2}}\right) \times 10^{3}$ & - \\
\hline $\begin{array}{l}\text { Simplified } \\
\text { Kingery } \\
{[21]}\end{array}$ & $\begin{array}{c}\left.\operatorname{EXP}\left(\begin{array}{c}9.006-2.6893 \ln Z-0.6295 \ln Z^{2}+0.1011 \ln Z^{3} \\
+0.29255 \ln Z^{4}+0.13505 \ln Z^{5}+0.019736 \ln Z^{6}\end{array}\right)\right] / R_{c} \\
{\left[\operatorname{EXP}\left(\begin{array}{c}8.8396-1.733 \ln Z-2.64 \ln Z^{2}+2.293 \ln Z^{3} \\
-0.8232 \ln Z^{4}+0.14247 \ln Z^{5}-0.0099 \ln Z^{6}\end{array}\right)\right] / R_{c}}\end{array}$ & $\begin{array}{l}(0.06<Z<2.0) \\
(2.0<Z<40.0)\end{array}$ \\
\hline $\begin{array}{c}\text { Kinney } \\
\& \text { Graham [16] }\end{array}$ & $98.07 P_{0} \frac{}{\left(\sqrt{1+\left(\frac{Z}{0.048}\right)^{2}}\right)\left(\sqrt{1+\left(\frac{Z}{0.32}\right)}\right.}$ & - \\
\hline Mills [22] & $\frac{108}{Z}-\frac{114}{Z^{2}}+\frac{1772}{Z^{3}}$ & - \\
\hline $\begin{array}{l}\text { Sadovskiy } \\
{[23]}\end{array}$ & $\left(\frac{0.085}{Z}+\frac{0.3}{Z^{2}}+\frac{0.8}{Z^{3}}\right) \times 10^{3}$ & - \\
\hline $\begin{array}{l}\text { Bajic [24] } \\
\text { (modified } \\
\text { Sadovskiy) }\end{array}$ & $98.07\left(\frac{1.02}{Z}+\frac{4.36}{Z^{2}}+\frac{14}{Z^{3}}\right)$ & - \\
\hline
\end{tabular}

than the original incident overpressure, $P(t)$. The reflected overpressure, $P_{r}$, can be evaluated from Eq. (3) by multiplying the incident overpressure with a refraction coefficient, $R_{c}$, given by the imperial [17] equation (4):

$$
\begin{aligned}
& P_{r}(t)=R_{c} P_{s o}\left(1-\frac{t}{t_{d}}\right) e^{-b \frac{t}{t_{d}}}, \\
& R_{c}=\frac{8 P_{s o}+14 P_{0}}{P_{s o}+7 P_{0}} .
\end{aligned}
$$

The physical impact of a detonation on a given structure can be described analytically by the reflected pressure. Therefore, in order to examine the damage potential of detonation effectively, the corresponding reflected pressure must be predicted with sufficient accuracy. An inspection of Eq. (3) indicates that the key parameters in evaluating the reflected pressure are the magnitude of peak overpressure, $P_{\text {so }}$, and the time duration of the overpressure phase, $t_{d}$.

Table 1 contains a series of empirical equations developed by various researchers since 1955 to predict 
peak overpressure, $P_{\text {so }}$. Figure 2 shows the variation of peak overpressure, $P_{\text {so }}$, with respect to the scaled distance, $Z$, for the equations cited in Table 1 . For simplicity, a unit charge weight (i.e., $W=1 \mathrm{~kg}$ ) is assumed for all of the curves plotted in Figure 2. With this assumption, scaled distance $Z$ will represent the physical distance from the source of explosion.

As seen in Figure 2, at relatively low values of the scaled distance (say $Z<1 \mathrm{~m} / \mathrm{kg}^{1 / 3}$ ), in general, a significant discrepancy exists between the peak overpressure values predicted by various equations. This discrepancy, however, is decreased with increasing values of the scaled distance. For scaled distance values of greater than $3 \mathrm{~m} / \mathrm{kg}^{1 / 3}$, any difference between the outcomes of the equations becomes insignificant. Therefore, the selection of an appropriate equation to

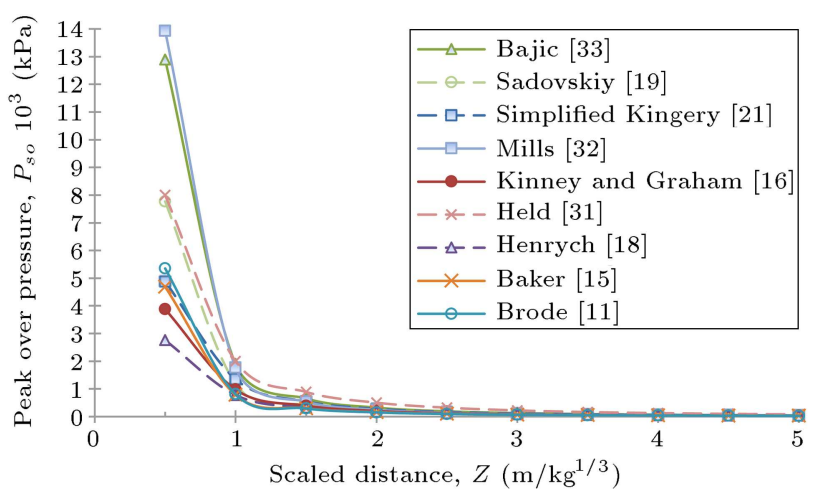

Figure 2. Variation of peak over pressure with scaled distance for $1 \mathrm{~kg}$ TNT explosive. predict the peak overpressure is critical only for scaled distance values of $3 \mathrm{~m} / \mathrm{kg}^{1 / 3}$ and less. As such, this paper is focused on $Z \leq 3 \mathrm{~m} / \mathrm{kg}^{1 / 3}$.

Table 2 includes the empirical equations developed by various researchers to evaluate $t_{d}$ as another key parameter that influences the magnitude of reflected pressure in Eq. (3). In general, $t_{d}$ is affected by the charge weight, $W$, and the distance to the center of the explosive, $R$. As such, in the equations cited in Table $2, t_{d}$ is described in terms of scaled distance $Z$.

Figure 3 shows the relationship between time duration $t_{d}$ and scaled distance $Z$ for various empirical equations cited in Table 2. To be consistent with the assumptions made in producing Figure 2, a unit $(1 \mathrm{~kg})$ charge weight has been taken into account in the

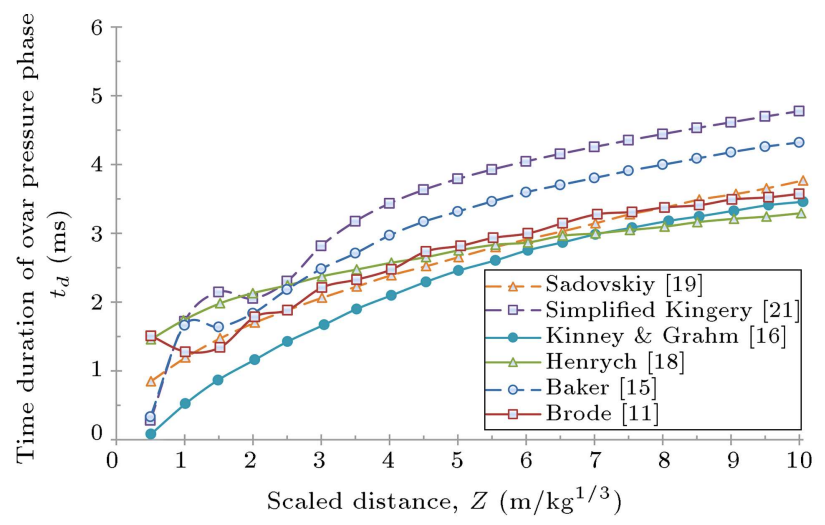

Figure 3. Relationship between the time duration of the overpressure phase and scaled distance for $1 \mathrm{~kg}$ TNT explosive.

Table 2. Empirical models for the time duration, $t_{d}$, of the overpressure phase.

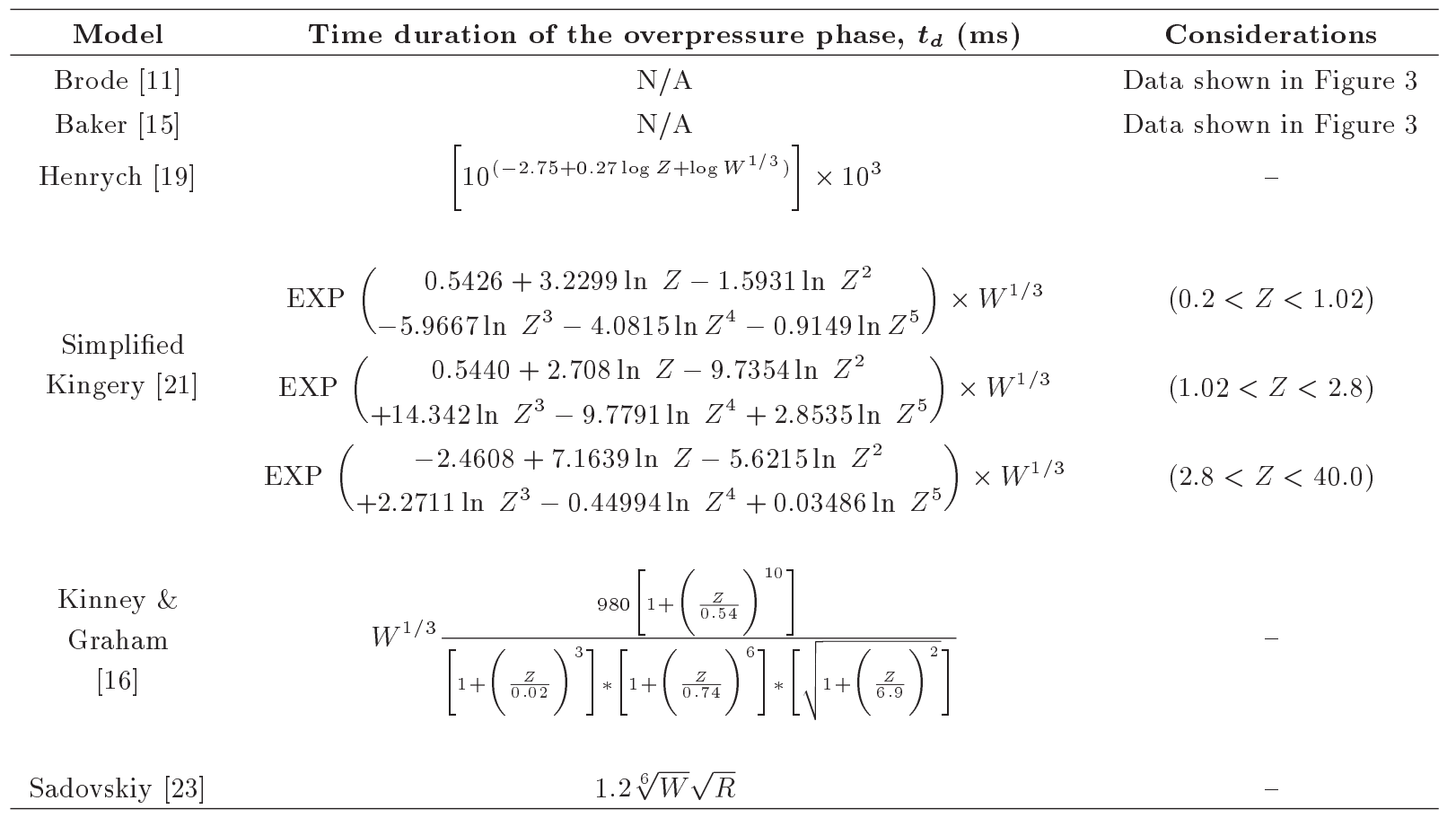


Table 3. Specification of the experimental studies [5,25,26].

\begin{tabular}{|c|c|c|c|c|c|c|c|c|c|c|}
\hline Test & $\begin{array}{c}\text { Slab } \\
\text { name }\end{array}$ & $\begin{array}{l}\text { Dimensions } \\
\qquad(\mathrm{mm})\end{array}$ & $\begin{array}{c}\text { Rebar } \\
\text { ratio } \\
(\mathrm{x})\end{array}$ & $\begin{array}{c}\text { Rebar } \\
\text { ratio } \\
(y)\end{array}$ & $\begin{array}{c}\text { Standoff } \\
\text { distance } \\
(\mathrm{m})\end{array}$ & $\begin{array}{c}\text { Explosive } \\
\text { mass } \\
(\mathrm{kg})\end{array}$ & $\begin{array}{c}\text { Scaled } \\
\text { distance } \\
\left(\frac{\mathrm{m}}{\mathrm{kg}^{1 / 3}}\right)\end{array}$ & $\begin{array}{c}\text { Central } \\
\text { deflection } \\
\delta(\mathrm{mm})\end{array}$ & $\delta / h$ & $\begin{array}{c}\text { Spall } \\
\text { radius } \\
(\mathrm{mm})\end{array}$ \\
\hline NRC-1 & A & $750 \times 750 \times 30$ & $1.43 \%$ & $1.43 \%$ & 0.3 & 0.13 & 0.592 & 9 & 0.300 & 50 \\
\hline NRC-2 & A & $750 \times 750 \times 30$ & $1.43 \%$ & $1.43 \%$ & 0.3 & 0.19 & 0.522 & 26 & 0.867 & 85 \\
\hline NRC-3 & B & $1000 \times 1000 \times 40$ & $1.43 \%$ & $1.43 \%$ & 0.4 & 0.2 & 0.684 & 10 & 0.250 & - \\
\hline NRC-4 & $\mathrm{C}$ & $1250 \times 1250 \times 50$ & $1.43 \%$ & $1.43 \%$ & 0.5 & 0.64 & 0.580 & 19 & 0.380 & 120 \\
\hline NRC-5 & $\mathrm{D}$ & $2000 \times 1000 \times 100$ & $1.34 \%$ & $0.74 \%$ & 3.0 & 1.007 & 2.993 & 1.5 & 0.015 & - \\
\hline NRC-6 & $\mathrm{D}$ & $2000 \times 1000 \times 100$ & $1.34 \%$ & $0.74 \%$ & 3.0 & 8.139 & 1.490 & 10.5 & 0.105 & - \\
\hline NRC-7 & $\mathrm{D}$ & $2000 \times 1000 \times 100$ & $1.34 \%$ & $0.74 \%$ & 1.4 & 3.440 & 0.927 & 13.9 & 0.139 & - \\
\hline NRC-8 & $\mathrm{D}$ & $2000 \times 1000 \times 100$ & $1.34 \%$ & $0.74 \%$ & 1.5 & 8.213 & 0.743 & 38.9 & 0.389 & - \\
\hline
\end{tabular}

evaluation of $t_{d}$ in Figure 3 . An examination of Figure 3 indicates that the models developed by Henrych [18], Kinney and Graham [16], and Sadovskiy [19] show a monotonically increasing trend, regardless of the magnitude of scaled distance $Z$. However, this phenomenon cannot be observed in the time duration values predicted by the other models. The time duration versus distance curve that is simulated by Brode [11] fluctuates approximately throughout the entire range of $Z$ values shown in Figure 3. The simplified Kingery [20] model and the model developed by Baker [15] experience fluctuations until $Z$ values of approximately $2 \mathrm{~m} / \mathrm{kg}^{1 / 3}$. The time duration predicted by these models increases monotonically with increasing $Z$ for distances beyond $2 \mathrm{~m} / \mathrm{kg}^{1 / 3}$.

A close examination of Figure 3 indicates that the time duration predicted by Kinney and Graham model [16] is a lower bound to the other models until a scaled distance of approximately $Z=7 \mathrm{~m} / \mathrm{kg}^{1 / 3}$. On the contrary, the simplified Kingery model [20] provides an upper bound to the rest of the models for approximately all $Z$ values with an exception for $Z<1 \mathrm{~m} / \mathrm{kg}^{1 / 3}$, where the time duration predicted by the model is significantly lower than the other models, excluding Kinney and Graham model. Overall, the time duration predicted by the simplified Kingery [20] and Baker [15] models is significantly longer than that of the other models for $Z>3 \mathrm{~m} / \mathrm{kg}^{1 / 3}$. Given the substantial discrepancies that exist between the time durations predicted by the models at any given $Z$, the selection of an appropriate model for the effective prediction of $t_{d}$ is quite essential.

In the following sections of the paper, the effectiveness of the empirical models listed in Tables 1 and 2 in the prediction of peak magnitude and time duration of blast-overpressure will be investigated by comparing the results of finite-element analysis models with the previous experimental studies available in the literature.

\section{Experimental studies}

Results of a set of various experimental studies carried out by Wu et al. [21], and Wang et al. [5,22] on different specimens of reinforced concrete slabs were selected to examine the accuracy of the empirical equations cited in Tables 1 and 2. The specifications of the test specimens, the mass of TNT explosive, and its standoff distance from the specimen are cited in Table 3.

Specimens A and C [22] and specimen B [5] were reinforced using a reinforcement mesh comprising rebars of $6 \mathrm{~mm}$ diameter in both directions and a mesh size of $75 \mathrm{~mm} \times 75 \mathrm{~mm}$. For specimen D [21], the mesh size was $200 \mathrm{~mm} \times 200 \mathrm{~mm}$, and the diameter of the reinforcing bars was $12 \mathrm{~mm}$. The compressive strength and Young's modulus of concrete for all specimens were reported to be $39.5 \mathrm{MPa}$ and 28.3 $\mathrm{GPa}$, respectively. The tensile strength of concrete was measured to be $4.2 \mathrm{MPa}$ for specimens $\mathrm{A}, \mathrm{B}$, and $\mathrm{C}$, and $8.2 \mathrm{MPa}$ for specimen $\mathrm{D}$. The yield strength and Young's modulus of the reinforcing bars were $600 \mathrm{MPa}$ and $200 \mathrm{GPa}$, respectively.

\section{Finite-element modeling of test specimens}

This section describes the 3D FE models that are developed to investigate the effectiveness of the empirical equations cited in Tables 1 and 2 in blast response prediction of the concrete slabs listed in Table 3. The explicit nonlinear finite-element program ANSYS AUTODYN [23] has been used in this research study for geometric modeling and impact analysis of the concrete slab specimens. AUTODYN [23] and LSDYNA [24] programs have been successfully employed in blast analysis of RC-slabs by many researchers (e.g., Wang et al. [5], Tai et al. [3], Zhao and Chen [4], and Thiagarajan et al. [25]). In this paper, the loading function relevant to detonation of an explosive charge located at a specific standoff distance from the center 

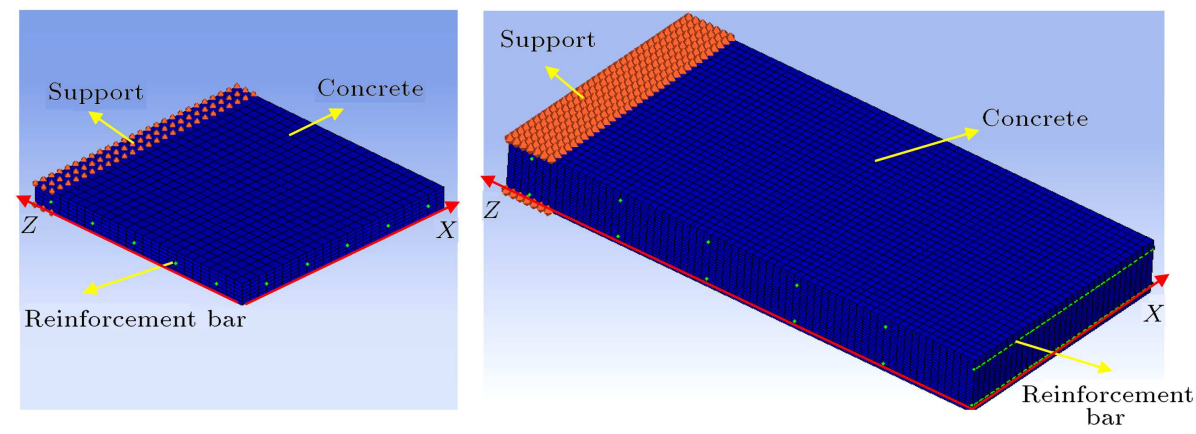

Figure 4. 3D finite-element model of concrete slab test specimens.

of concrete slab has been simulated using the timedependent Eq. (3). The peak overpressure and the time duration in the said equation have been evaluated using a desired combination of models given in Tables 1 and 2 , respectively. The wave decay parameter, $b$, has been calculated using Eq. (2).

Due to symmetry, only a quarter of the concrete slab is modeled in the FE analysis (see Figure 4). As shown in Figure 4, in order to simulate a fixed boundary condition, at the supporting edge of the slab, all degrees of freedom are restrained on both upper and lower faces of the slab. The reinforcing bars within the slab are modeled using the "beam solver" available in the program. The beam solver is employed for one-dimensional parts such as reinforcing bars. When used in conjunction with solid elements, beams (i.e., the reinforcing bars) can be located inside a solid element without being aligned with the nodes of the Lagrangian solid elements, making their use unlimited, while requiring very little effort to set up the model [23]. The concrete material within the slab is modeled using the "Lagrangian solver" as an analysis option available in AUTODYN [23]. In the FE model, a perfect bond is assumed between reinforcing bars and their surrounding concrete. A brief description of the constitutive models employed for concrete and steel materials is given in the two following subsections.

\subsection{Material model for concrete}

Under blast loads, the mechanical properties of concrete will be significantly altered as a result of the high straining (loading) rate of the material. Thus, it is quite essential to use a constitutive material model that addresses the high-strain rate effects. The FE models presented in this paper employ the Riedel, Hiermaier and Thoma (RHT) [26] dynamic damage model for the concrete material. The RHT model addresses various response mechanisms that are found in brittle materials. These include pressure and strain hardening, strain rate effects, third invariant dependence for compressive and tensile meridians, strain softening, and cumulative damage. The model also includes the P-alpha equation of state for volumetric compaction [27]. The RHT model employs three strength surfaces: an elastic limit surface, a failure surface, and the remaining strength surface for the crushed material. A detailed description of the model can be found in Riedel et al. [26].

The strength and failure parameters adopted for the RHT model in this research study are the following constant values that are typically adopted for an ordinary concrete material [23,28].

- The reference density, $\rho=2.75 \mathrm{~g} / \mathrm{cm}^{3}$;

- Shear modulus, $G=11.79 \mathrm{GPa}$;

- Compressive strength, $f_{c}=39.5 \mathrm{MPa}$;

- Tensile strength, $f_{t}=4.2 \mathrm{MPa}$ for slabs A, B, C and $f_{t}=8.2 \mathrm{MPa}$ for slab $\mathrm{D}$;

- Intact failure surface constant, $A=1.6$;

- Intact failure surface exponent, $N=0.61$;

- Meridian ratio, $Q=0.6805$;

- Fractured strength constant, $B=1.6$;

- Fractured strength exponent, $M=0.61$;

- Damage constants, $D_{1}=0.04 ; D_{2}=1$, $\varepsilon_{f}^{\min }=0.008$;

- A residual shear modulus fraction of 0.13.

Table 4 includes the AUTODYN [23] default values used for the parameters of the equation of state (EQS) of concrete. These values have been utilized in the FE modeling of the concrete slabs of this study. The EQS for concrete material includes two sets of polynomials that serve to model the material behavior under compression and tension load patterns, individually. Parameters $A_{1}, A_{2}, A_{3}$, and $B_{1}$ in Table 4 are the constant coefficients of the polynomial of the EQS when the concrete material is subjected to compression. Parameters $T_{1}$ and $T_{2}$ are the constant coefficients of the EQS when the concrete material undergoes tension. $B_{0}$ is a constant coefficient in the EQS that is used for both compression and tension cases. A detailed description of the mentioned polynomials can be found in [2]. 
Table 4. AUTODYN default values for the parameters of the equation of state of concrete.

\begin{tabular}{cccc}
\hline $\begin{array}{c}\text { P-alpha } \\
\text { EOS } \\
\text { parameters }\end{array}$ & Value & $\begin{array}{c}\text { Polynomial } \\
\text { EOS } \\
\text { parameters }\end{array}$ & Value \\
\hline Porous density, $\rho_{0}$ & $2.314 \mathrm{~g} / \mathrm{cm}^{3}$ & Bulk modulus, $A_{1}$ & $3.527 \mathrm{E} 7 \mathrm{kPa}$ \\
Porous sound speed, $C_{0}$ & $2.92 \mathrm{E} 3 \mathrm{~m} / \mathrm{s}$ & $A_{2}$ & $3.958 \mathrm{E} 7 \mathrm{kPa}$ \\
Initial compaction pressure, $P_{e}$ & $23.3 \mathrm{E} 3 \mathrm{kPa}$ & $A_{3}$ & $9.04 \mathrm{E} 6 \mathrm{kPa}$ \\
Solid compaction pressure, $P_{s}$ & $6 \mathrm{E} 6 \mathrm{kPa}$ & $B_{0}$ & 1.22 \\
Compaction exponent & 3.00 & $B_{1}$ & 1.22 \\
& & $T_{1}$ & $3.527 \mathrm{E} 7 \mathrm{kPa}$ \\
& & $T_{2}$ & 0.00 \\
& & Reference temperature & $300 \mathrm{~K}$ \\
& & Specific heat & $654 \mathrm{~J} / \mathrm{kgK}$ \\
& & Thermal conductivity & $0.00 \mathrm{~J} / \mathrm{mKs}$ \\
\hline
\end{tabular}

\subsection{Material model for reinforcing steel}

In this study, the steel reinforcement material has been modeled using the Johnson and Cook material model [29]. The model is particularly suitable for the simulation of strength behavior of the materials that are subjected to large strain values, high-strain rates, and high temperatures. The yield stress in the Johnson and Cook model is defined as follows [29]:

$$
\sigma=\left[A+B \varepsilon_{p}^{n}\right]\left[1+C \ln \frac{\dot{\varepsilon}_{p}}{\dot{\varepsilon}_{0}}\right]\left[1-T_{H}^{m}\right]
$$

where $A$ represents the basic yield stress at low strains; constant $B$ and exponent $n$ represent the strain hardening effects of the material; and $\varepsilon_{p}$ is an effective plastic strain. The second bracket in Eq. (5) represents the effect of strain rate; $C$ is a material constant; the ratio of $\dot{\varepsilon}_{p} / \dot{\varepsilon}_{0}$ represents the normalized effective plastic strain rate for $\dot{\varepsilon}_{0}=1$ $\mathrm{s}^{-1}$; the third bracket in Eq. (5) represents the effect of temperature; $T_{H}$ (the homologous temperature) is defined as $\left(T-T_{\text {room }}\right) /\left(T_{\text {melt }}-T_{\text {room }}\right)$, where $T$ is the absolute temperature, $T_{\text {room }}$ is room temperature, and $T_{\text {melt }}$ is melting temperature of steel. Parameter $m$ in Eq. (5) is a material constant.

The material constants adopted in the current paper are as follows:

- Reference density, $\rho=7.83 \mathrm{~g} / \mathrm{cm}^{3}$;

- Bulk modulus, $K=167 \mathrm{GPa}$;

- Reference room temperature, $T_{\text {room }}=300 \mathrm{~K}$;

- Specific heat of $477 \mathrm{~J} / \mathrm{kg} \mathrm{K}$;

- Thermal conductivity of $0.00 \mathrm{~J} / \mathrm{kg} \mathrm{K}$;

- Shear modulus, $G=76.92 \mathrm{GPa}$;

- Basic yield stress, $A=600 \mathrm{MPa}$;

- Strain hardening constants, $B=510 \mathrm{MPa}$;
- Strain hardening exponent, $n=0.26$;

- Strain rate constant, $C=0.014$;

- Thermal softening exponent, $m=1.03$;

- Melting temperature, $T_{\text {melt }}=1793 \mathrm{~K}$.

\subsection{Distribution of reflected pressure on the surface of specimens}

Results of a previous experimental study [21] indicate that the distribution of blast-reflected pressure on the surface of a specimen is highly influenced by the magnitude of scaled distance, $Z$, of the explosion. For $Z$ values greater than $3 \mathrm{~m} / \mathrm{kg}^{1 / 3}$, the distribution of blast pressure on the entire surface of specimen on the side facing the explosion will be approximately uniform. However, this is not the case when $Z$ acquires values less than $3 \mathrm{~m} / \mathrm{kg}^{1 / 3}$. If an explosive detonates at a relatively close standoff distance right above the center of a concrete slab specimen, the magnitude of blast pressure on the center of the specimen will be significantly larger than that on the corners of the specimen [21].

The $Z$ values in all of the $\mathrm{FE}$ analysis runs presented in this paper are smaller than $3 \mathrm{~m} / \mathrm{kg}^{1 / 3}$. As such, a non-uniform distribution for the blast pressure is required to be taken into account while conducting the analysis. To achieve this, the surface of concrete slab on the side facing the explosion is divided into square area segments of identical dimensions. For each individual area segment, the scaled distance is calculated based on the physical standoff distance of the explosive from the center of that area segment. When the scaled distance is evaluated for each segment, the peak overpressure and time duration of the overpressure phase of the explosion can be calculated using desired equations given in Tables 1 and 2, respectively. The blast reflected pressure for the area-segment of interest is calculated from Eq. (3). 


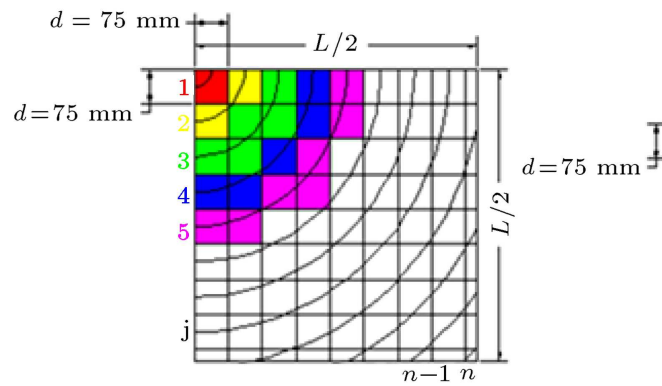

(a) Quarter slabs A, B, or C

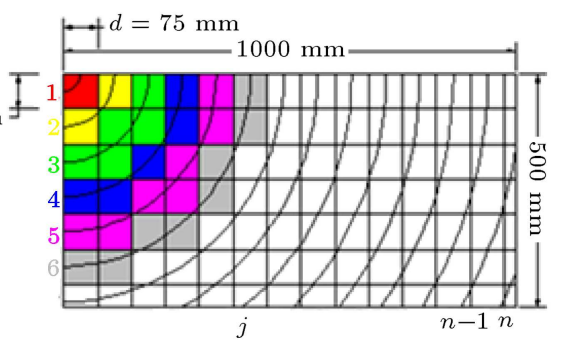

(b) Quarter slab D

Figure 5. Non-uniform distribution of blast loading on quarter slabs ( $L=750,1000,1250)$.

Figure 5(a) and (b) illustrate the procedure of dividing the surface of the concrete slabs into the areasegments. Since only $1 / 4$ of the slab is modeled (due to symmetry), the upper left corner of each quarter slab represents the center of the corresponding complete slab, and the spot of the explosive is located above it at a specific standoff distance. The area segments in Figure 5(a) and (b) are selected to be plane squares of $75 \times 75 \mathrm{~mm}$, which is a complete multiple of the size of finite elements used to discretize the slab. The contours shown in Figure 5(a) and (b) are the arcs of concentric circles that are plotted to cross the mid length of boundary segments.

In a simplified approach, an approximation on the effective scaled distance of explosive from area segment " $i$ " can be made as follows:

$$
Z_{i}=\frac{\sqrt{R^{2}+\left[\frac{d(2 j-1)}{2}\right]^{2}}}{W^{1 / 3}},
$$

where $R$ is the standoff distance of the explosive of weight $W$ from the center of the slab, and $j$ is the order of the arc circle that crosses area segment " $i$ " at the closest distance to the center of the segment. Parameter $d$ represents the dimension of the area segment. On the basis of Eq. (6), the scaled distance and, therefore, the blast pressure, for the typical area segments of the same color shown in Figure 5(a) and (b) will be identical.

In a more rigorous approach, to calculate the exact effective scaled distance, $Z_{i \text {,exact }}$, for the area segment " $i$ ", $R_{i}$ in Eq. (7) may be taken as the radius of an arc circle that crosses the center of the area segment of interest. It was found that the error values in the FE analysis results were insignificant when Eq. (6), rather than $Z_{i \text {,exact }}$, was employed to evaluate effective blast pressure on the area segments. The negligible error values are associated with the relatively small dimensions of the area segments in Figure 5(a) and (b). Accordingly, Eq. (6) was employed in all of the $\mathrm{FE}$ analysis runs conducted in this research due to its simplicity and ease of application.

$$
Z_{i, \text { exact }}=\frac{\sqrt{R^{2}+R_{i}^{2}}}{W^{1 / 3}}
$$

\subsection{Sensitivity analysis}

The FE analysis of a concrete slab under blast loading is in general sensitive to the size of the FE mesh and the dimensions of the area-segments, such as those shown in Figure 5. Mesh sensitivity analysis runs were performed to determine the optimum size of the finite elements (hereafter, concrete elements) that are required to discretize the concrete material within the slab specimens. Table 5 includes the results of $\mathrm{FE}$ analysis for three different analysis runs conducted on slab A in the test run NRC-1 (see Table 3). These analysis runs are identical in terms of the way the blast loading is defined and distributed all over the concrete slab (see Table 5). To define the blast loads, the empirical equations developed by Kinney and Graham [16] (see Tables 1 and 2) were used. Additionally, using the area segments of $75 \times 75 \mathrm{~mm}$, a non-uniform

Table 5. Results of mesh sensitivity analysis runs for test NRC-1 cited in Table 3.

\begin{tabular}{cccc}
\hline $\begin{array}{c}\text { Dimensions of } \\
\text { concrete } \\
\text { elements } \\
(\mathbf{m m})\end{array}$ & $\begin{array}{c}\text { Total number of } \\
\text { concrete } \\
\text { elements }\end{array}$ & $\begin{array}{c}\text { Error in the } \\
\text { evaluation of peak } \\
\text { deflection at the } \\
\text { center of } \\
\text { specimen }\end{array}$ & $\begin{array}{c}\text { Normalized analysis } \\
\text { elapsed time }\end{array}$ \\
\hline $25 \times 25 \times 5$ & 1350 & $-32.7 \%$ & 0.47 \\
$15 \times 15 \times 5$ & 3750 & $-5.8 \%$ & 1.00 \\
$12.5 \times 12.5 \times 5$ & 5400 & $-2.2 \%$ & 1.70 \\
\hline
\end{tabular}


distribution for the blast load on the concrete slabs was assumed according to the method stated in the previous sub-section. The element length used to define the steel reinforcement (i.e., steel elements) was selected to be $10 \mathrm{~mm}$ in each analysis. As such, each FE model in Table 5 comprises a total number of 380 steel elements.

An examination of Table 5 indicates that the accuracy of analysis is improved when concrete elements of smaller dimensions are employed in the FE mesh. When the concrete elements are of $25 \times 25 \times 5 \mathrm{~mm}$, the results of $\mathrm{FE}$ analysis are significantly unacceptable. The concrete elements of $15 \times 15 \times 5 \mathrm{~mm}$ provide sufficiently accurate approximation for the peak central slab deflection, as compared to the experimental data [22]. Although more accurate results are obtained when concrete elements of $12.5 \times 12.5 \times 5 \mathrm{~mm}$ are employed in the FE analysis, the analysis time is increased by $70 \%$ with respect to the concrete elements of $15 \times 15 \times 5 \mathrm{~mm}$. Given the objectives of this research study and the large number of analysis runs to be performed, the dimensions of concrete elements in the rest of $\mathrm{FE}$ analysis runs, with a compromise between analysis time and accuracy, were chosen to be $15 \times 15 \times 5 \mathrm{~mm}$.

The second component of sensitivity analysis includes investigation of the influence of the size of areasegments that are defined to provide a non-uniform distribution of blast loads across the concrete slab. To achieve this, the test runs NRC-1, NRC-2, and NRC-3 cited in Table 3 were modeled using area-segments of different dimensions, namely 75 and $120 \mathrm{~mm}$. These dimensions were selected as such to be a complete multiple of the size of concrete elements (i.e., $15 \times 15 \times 5$ $\mathrm{mm}$ ) in the FE mesh. In an additional third analysis run, the blast load was distributed uniformly all over the concrete slabs.

Figure 6 gives the absolute value of error in calculating the peak deflection at the center of concrete slabs in different analysis runs. As observed, the results of FE analysis are significantly unacceptable when a uniform distribution is assumed for blast loads all over the concrete slab. In such a case, the central deflection is underestimated by approximately $50 \%$.

The FE analysis results are significantly improved when the blast load is distributed non-uniformly over the concrete slabs in conformity with the method discussed in the previous sub-section. The use of area segments of $120 \mathrm{~mm}$ significantly decreased the error in estimating the peak central deflections of the slabs. Further improvement in the accuracy of analysis (less than $10 \%$ error) is obtained with the aid of area segments of $75 \times 75 \mathrm{~mm}$ (see Figure 6 ). As such, the size of area segments is considered to be $75 \times 75 \mathrm{~mm}$ for the FE analysis runs carried out in this research study.

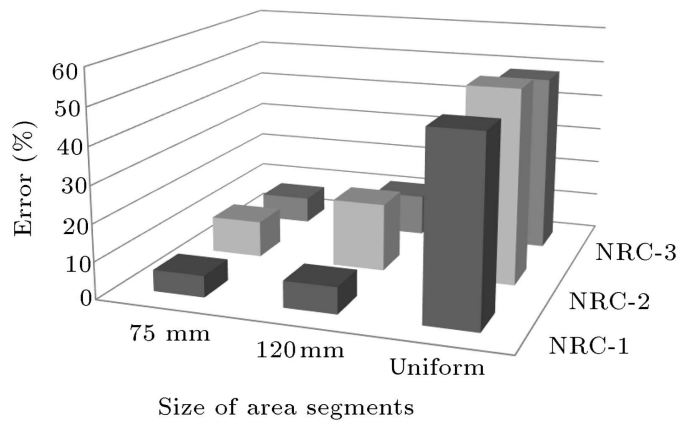

\begin{tabular}{|l|ccc|}
\cline { 2 - 4 } \multicolumn{1}{l|}{ Test } & $75 \mathrm{~mm}$ & $120 \mathrm{~mm}$ & Uniform \\
\hline NRC-1 & $5.78 \%$ & $7.11 \%$ & $49.22 \%$ \\
NRC-2 & $9.88 \%$ & $18.38 \%$ & $52.42 \%$ \\
NRC-3 & $7.20 \%$ & $11.20 \%$ & $48.30 \%$ \\
\hline
\end{tabular}

Figure 6. The influence of the size of area segments used for non-uniform distribution of blast loads on the accuracy of analysis (values reflect the errors achieved in the evaluation of peak deflection at the center of slab specimens).

\section{Finite-element analysis results and discussion}

Figure 7 includes the error values associated with the simulation of peak central deflection of the slab specimens in tests NRC-5 and NRC-6. The peak magnitude and time duration of the blast overpressure in the FE-analysis are evaluated using a pair of equations developed by various researchers (see Tables 1 and 2).

Given the scaled distance, $Z$, of $3 \mathrm{~m} / \mathrm{kg}^{1 / 3}$ in test NRC-5, the magnitudes of peak overpressure using the equations developed by Brode [11], Henrych [18], Kinney and Graham [16], and Sadovskiy [19] (see Table 1) are calculated to be $67,77.5,80$, and $91 \mathrm{kPa}$, respectively. The time duration of overpressure phase is estimated to be $1.68 \mathrm{~ms}$ by Kinney and Graham model [16], which is the lowest value among the rest of models shown in Figure 3. According to Figure 7, the magnitude of error in evaluation of peak deflection at the center of test NRC-5 is approximately $1.3 \%$ in Kinney and Graham [16] and 5\% in Brode [11] model. The error associated with Sadovskiy [19], simplified Kingery [20], Henrych [18], and Baker [15] models is significantly large.

An examination of Figure 7 shows that similar to test NRC-5, the accuracy of Kinney and Graham [16] model for test NRC-6 is superior to that of the rest of models, where the peak central deflection is estimated with only $1.7 \%$ error. It should be noted that the scaled-distance for NRC-6 is $1.5 \mathrm{~m} / \mathrm{kg}^{1 / 3}$. Brode [11] model provides the second best estimation of the deflection by an error value of slightly larger than $5 \%$.

It appears that, for the tests shown in Figure 7, the simulation of effects of explosion (i.e., the area under time-pressure curve is called hereafter as "blastimpact") is relatively more reasonable in both Kinney 


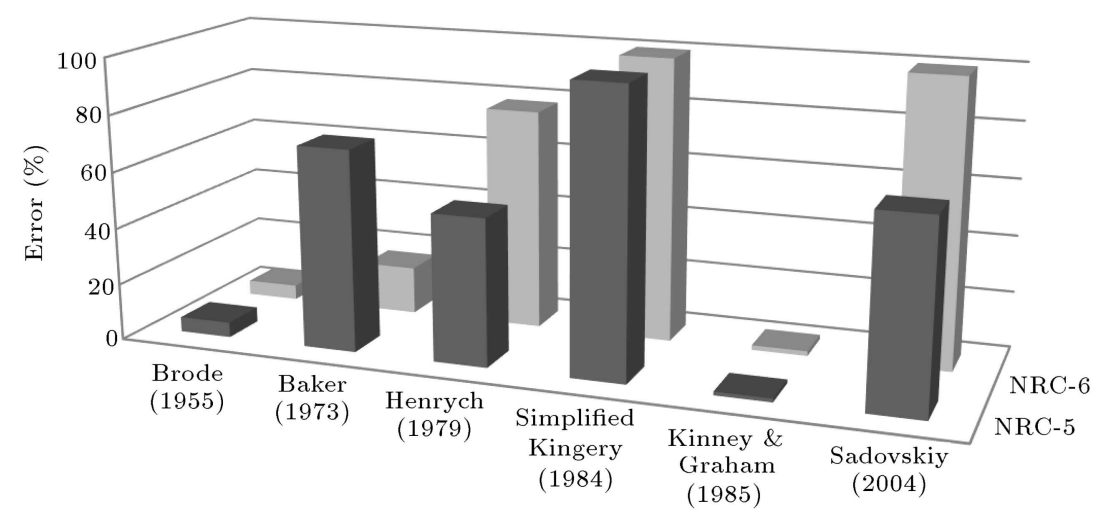

\begin{tabular}{|c|cccccc|}
\cline { 2 - 6 } \multicolumn{1}{c|}{ Test } & $\begin{array}{c}\text { Brode } \\
(1955)\end{array}$ & $\begin{array}{c}\text { Baker } \\
(1973)\end{array}$ & $\begin{array}{c}\text { Henrych } \\
(1979)\end{array}$ & $\begin{array}{c}\text { Simplified } \\
\text { Kingery } \\
(1984)\end{array}$ & $\begin{array}{c}\text { Kinney \& } \\
\text { Graham } \\
(1985)\end{array}$ & $\begin{array}{c}\text { Sadovskiy } \\
(2004)\end{array}$ \\
\hline NRC-5 & $5 \%$ & $71.30 \%$ & $52 \%$ & $e \gg 100 \%$ & $1.30 \%$ & $66.2 \%$ \\
NRC-6 & $5.20 \%$ & $16.80 \%$ & $78.2 \%$ & $e \gg 100 \%$ & $1.70 \%$ & $e \gg 100 \%$ \\
\hline
\end{tabular}

Figure 7. Accuracy of various models in the simulation of blast loads on test NRC-5 and NRC-6 with scaled-distance values of 3 and $1.5 \mathrm{~m} / \mathrm{kg}^{1 / 3}$, respectively. The error values are relevant to the peak central deflection of specimens.

and Graham [16] and Brode [11] models. For test NRC-5 $\left(Z=3 \mathrm{~m} / \mathrm{kg}^{1 / 3}\right)$, the blast-impact estimated by Sadovskiy [19] and Henrych [18] models is approximately $50 \%$ larger than that by Kinney and Graham [16] model. For this test, Baker [15] and simplified Kingery [20] models further overestimate the blast-impact. According to Figure 7, the accuracy of Baker [15] model is significantly improved for test NRC-6 $\left(Z=1.5 \mathrm{~m} / \mathrm{kg}^{1 / 3}\right)$. The overpressure of Baker [15] model for NRC-6 is slightly smaller than that of Kinney and Graham [16], and its time duration is approximately $30 \%$ longer. As such, the magnitude of blast-impact simulated by Baker [15] model for test NRC-6 is not as unacceptable as that for test NRC5. This leads to an approximately $17 \%$ error in the evaluation of the peak central deflection in test NRC-6 that is significantly smaller than $71 \%$ error obtained for test NRC-5.

A close examination of Figure 7 indicates that, except for Kinney and Graham [16] model, the rest of models have overestimated the peak central deflection and the magnitude of blast-impact. The error values in evaluation of peak deflections at the center of slabs for tests NRC-1 to NRC-4, NRC-7, and NRC-8, with $Z$ values ranging from 0.5 to $1.0 \mathrm{~m} / \mathrm{kg}^{1 / 3}$, are less than $11 \%$ when the empirical equations developed by Kinney and Graham [16] are used in evaluation of both peak magnitude and time duration of overpressure. Results of the other empirical equations are significantly unacceptable for the aforementioned tests.

The range of scaled distance, $Z$, for the test specimens of this research study is between 0.5 to 3 $\mathrm{m} / \mathrm{kg}^{1 / 3}$. According to Figure 3 , for this range of $Z$ values, Kinney and Graham [16] model provides a lower bound to the time duration of overpressure phase of explosion, $t_{d}$. Accordingly, to increase the accuracy of analysis, in the rest of FE analysis runs conducted in this paper, $t_{d}$ is calculated using Kinney and Graham [16] model (see Table 2). This is in contrast with the model used to estimate the peak overpressure, since, according to Figure 2, the values of peak overpressure evaluated by various models are not in general as unacceptable as those of $t_{d}$, especially for $Z$ values larger than $1 \mathrm{~m} / \mathrm{kg}^{1 / 3}$.

For the tests NRC-1 and NRC-2 shown in Figure 8 and test NRC-4 in Figure 9, the error values in evaluation of central peak deflection using Brode [11], Baker [15], and Kinney and Graham [16] models are between $2 \%$ to $15 \%$, which are reasonably low. The scaled distance, $Z$, for these tests is between 0.5 to $0.6 \mathrm{~m} / \mathrm{kg}^{1 / 3}$. According to Figure 2 and Table 1, for this range of $Z$ values, the magnitude of peak overpressure and, therefore, the blast-impact evaluated by Brode [11], Baker [15], and Kinney and Graham [16] equations are comparable. For test NRC-3 with $Z$ of approximately $7 \mathrm{~m} / \mathrm{kg}^{1 / 3}$, only the results of Kinney and Graham [16] model are satisfactory.

According to Figure 9, for test NRC-5, the result of Henrych [18] model is around $5 \%$ off. The blastimpacts simulated by Kinney and Graham [16] and Henrych [18] models are comparable. Brode [11] model also provides an accurate result for this test.

Given the $Z$ value of test NRC-6, namely $1.5 \mathrm{~m} / \mathrm{kg}^{1 / 3}$, the magnitudes of peak overpressure using Kinney and Graham [16] and Sadovskiy [19] models (Table 1) are calculated to be $393 \mathrm{kPa}$ and $427 \mathrm{kPa}$, respectively. The magnitude of error in the evaluation of peak central deflection is approximately 


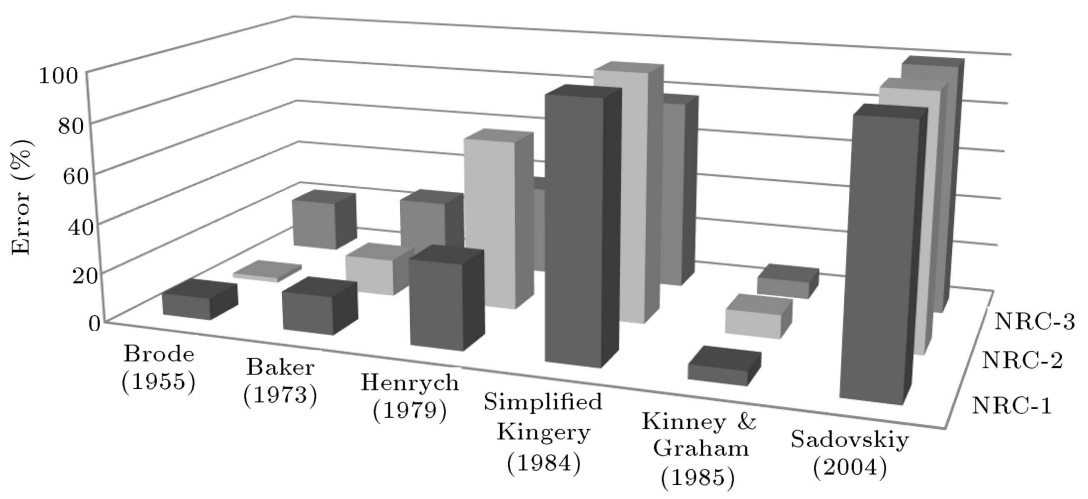

\begin{tabular}{|l|cccccc|}
\cline { 2 - 7 } \multicolumn{1}{l|}{ Test } & $\begin{array}{r}\text { Brode } \\
(1955)\end{array}$ & $\begin{array}{c}\text { Baker } \\
(1973)\end{array}$ & $\begin{array}{c}\text { Henrych } \\
(1979)\end{array}$ & $\begin{array}{c}\text { Simplified } \\
\text { Kingery } \\
(1984)\end{array}$ & $\begin{array}{c}\text { Kinney \& } \\
\text { Graham } \\
(1985)\end{array}$ & $\begin{array}{c}\text { Sadovskiy } \\
(2004)\end{array}$ \\
\hline$\square$ NRC-1 & $9 \%$ & $15.50 \%$ & $34 \%$ & $e \gg 100 \%$ & $5.70 \%$ & $e \gg 100 \%$ \\
$\square$ NRC-2 & $2 \%$ & $15.20 \%$ & $69.10 \%$ & $e \gg 100 \%$ & $9.80 \%$ & $e \gg 100 \%$ \\
$\square$ NRC-3 & $21.60 \%$ & $26.30 \%$ & $36.80 \%$ & $78.10 \%$ & $7.20 \%$ & $100 \%$ \\
\hline
\end{tabular}

Figure 8. Error in the prediction of peak central deflection (all of the models use Kinney and Graham [16] time duration, $t_{d}$, in the analysis; $Z$ values are between 0.5 and $\left.0.7 \mathrm{~m} / \mathrm{kg}^{1 / 3}\right)$.

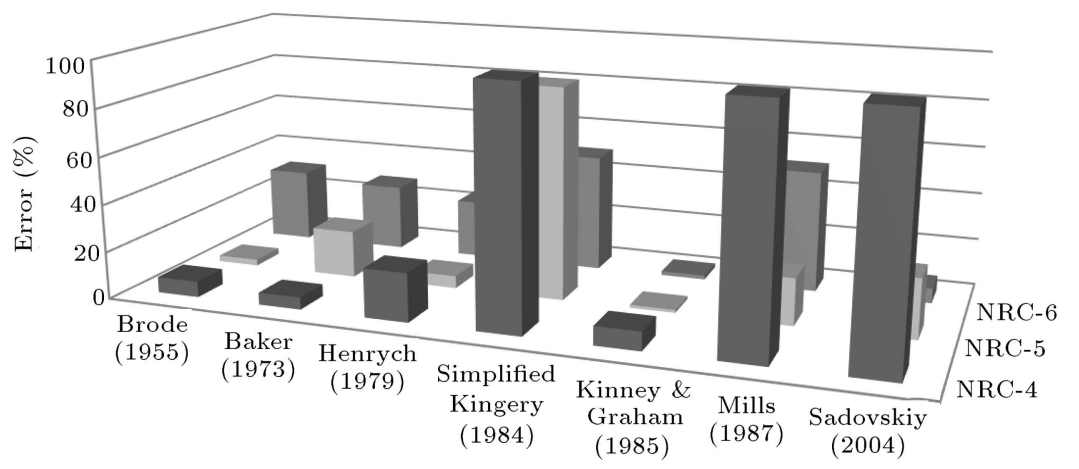

\begin{tabular}{|c|c|c|c|c|c|c|c|}
\hline Test & $\begin{array}{l}\text { Brode } \\
(1955)\end{array}$ & $\begin{array}{c}\text { Baker } \\
(1973)\end{array}$ & $\begin{array}{c}\text { Henrych } \\
(1979)\end{array}$ & $\begin{array}{c}\text { Simplified } \\
\text { Kingery } \\
(1984)\end{array}$ & $\begin{array}{c}\text { Kinney \& } \\
\text { Graham } \\
\text { (1985) }\end{array}$ & $\begin{array}{l}\text { Mills } \\
(1987)\end{array}$ & $\begin{array}{l}\text { Sadovskiy } \\
(2004)\end{array}$ \\
\hline NRC-4 & $7 \%$ & $5.20 \%$ & $20.80 \%$ & $e \gg 100 \%$ & $8.00 \%$ & $e \gg 100 \%$ & \\
\hline NRC-5 & $2.60 \%$ & $20.00 \%$ & $5.30 \%$ & $89.30 \%$ & $1.30 \%$ & $20 \%$ & $25.30 \%$ \\
\hline NRC-6 & $31.10 \%$ & $28.20 \%$ & $24.70 \%$ & $49.70 \%$ & $1.70 \%$ & $51.10 \%$ & $6.40 \%$ \\
\hline
\end{tabular}

Figure 9. Error in the prediction of peak central deflection (all of the models use Kinney and Graham [16] time duration, $t_{d}$, in the analysis; $Z$ values are between 0.5 and $\left.3.0 \mathrm{~m} / \mathrm{kg}^{1 / 3}\right)$.

$6.4 \%$ when the peak overpressure is calculated using Sadovskiy [17] model. This suggests that the model has been able to reasonably simulate the blast-impact for test NRC-6. As with the previous test, for NRC-6, the results obtained by Kinney and Graham [16] model are superior to those by the rest of models presented in this research study.

Figure 10 contains the analysis results of tests NRC-7 and NRC-8 with Z values of 0.93 and 0.75 , respectively. For both tests, the magnitude of error in the prediction of peak central deflection is minimal (around $9 \%$ to $11 \%$ ) when the peak overpressure is calculated using Kinney and Graham [16] model. The results of the other models are significantly unsatisfactory. It should be noted that the results of Newmark and Hansen [30], Held [31], Mills [32], and Bajic [33] are excluded in Figures 8-10 due to their significantly large error values in prediction of peak central deflection.

A close examination of Figures 8-10 indicates that the use of Kinney and Graham [16] time duration, $t_{d}$, generally improves the efficiency of various models in the simulation of the peak overpressure and, therefore, the blast-impact. However, when Kinney and Graham [16] peak overpressure together with 


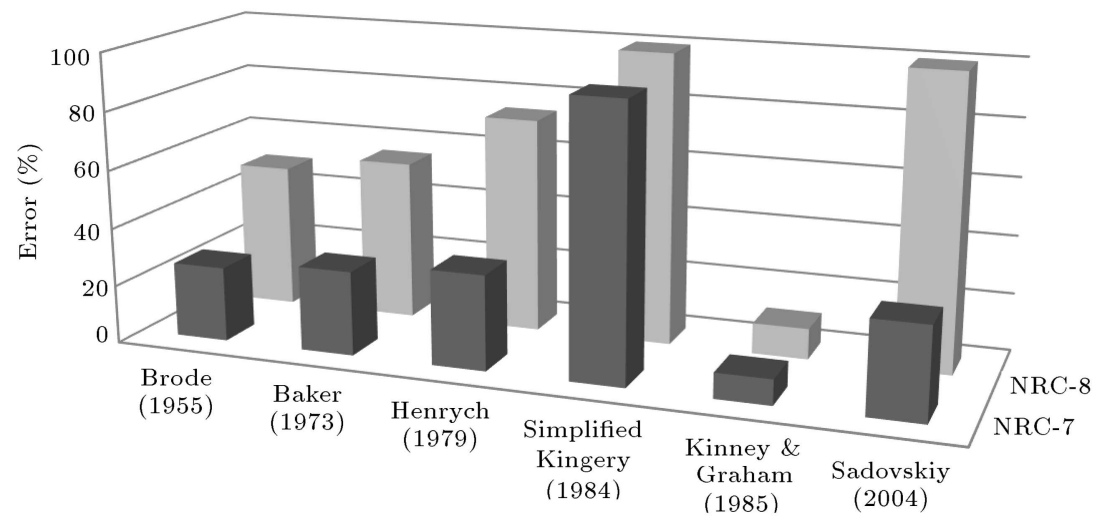

\begin{tabular}{|l|cccccc|}
\cline { 2 - 6 } \multicolumn{1}{c|}{ Test } & $\begin{array}{c}\text { Brode } \\
(1955)\end{array}$ & $\begin{array}{c}\text { Baker } \\
(1973)\end{array}$ & $\begin{array}{c}\text { Henrych } \\
(1979)\end{array}$ & $\begin{array}{c}\text { Simplified } \\
\text { Kingery } \\
(1984)\end{array}$ & $\begin{array}{c}\text { Kinney \& } \\
\text { Graham } \\
(1985)\end{array}$ & $\begin{array}{c}\text { Sadovskiy } \\
(2004)\end{array}$ \\
\hline NRC-7 & $26 \%$ & $29.10 \%$ & $32.80 \%$ & $93.70 \%$ & $8.80 \%$ & $31.90 \%$ \\
NRC-8 & $49.80 \%$ & $55.20 \%$ & $74.10 \%$ & $e \gg 100 \%$ & $10.70 \%$ & $e \gg 100.00 \%$ \\
\hline
\end{tabular}

Figure 10. Error in the prediction of peak central deflection (all of the models use Kinney and Graham [16] time duration, $t_{d}$, in the analysis; $Z$ values are between 0.7 and $\left.1.0 \mathrm{~m} / \mathrm{kg}^{1 / 3}\right)$.

their $t_{d}$ is employed to carry out the analysis, the results will be more accurate than the experimental results. To further examine the efficiency of Kinney and Graham [16] model in the simulation of blast load effects, the damage patterns of tests NRC-1 to NRC4 are evaluated via FE analysis and, then, compared with experimental observations. It should be noted that among the tests listed in Table 3, the damage pattern has been reported only for these four tests.

According to Figure 11(a) and (b), the FE analysis could not predict the few longitudinal cracks formed on the top face, in addition to the mid-span crack (see Figure 11(a)). It is postulated that, in the FE model, the slab specimen has been subjected to slightly smaller overpressure, as compared to its status in reality. As such, the damage pattern simulated in the analysis has not been as severe as that in the experimental observations.

The severe spalling at the mid span of the specimen (Figure 11(c)) has been well predicted by the FE analysis (Figure 11(d)). The radius of spalling in the experimental test has been reported [9] to be approximately $50 \mathrm{~mm}$. The $\mathrm{FE}$ analysis predicts a spalling radius of $45 \mathrm{~mm}$, which is around $10 \%$ lower than the experimental observations. Another difference is the excessive level of damage that is observed in the FE analysis at the two opposite edges of the slab near the supports as the support condition in the FE analysis is more rigid than that in the experiment.

Figure 12 shows the damages occurred in test NRC-2. In the FE analysis, a major crack has occurred at the mid span of the slab that is consistent with experimental observations. Additionally, a number of cracks have been formed on a circular region around the

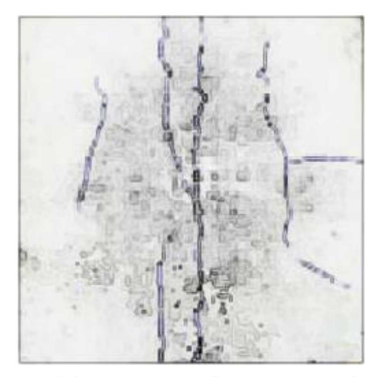

(a) Top face (experiment)

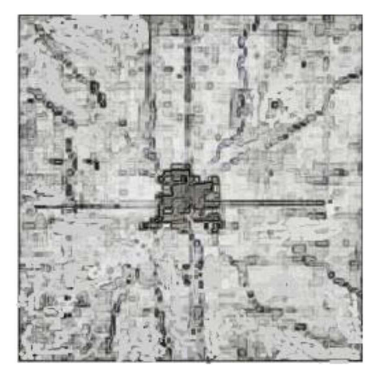

(c) Bottom face (experiment)

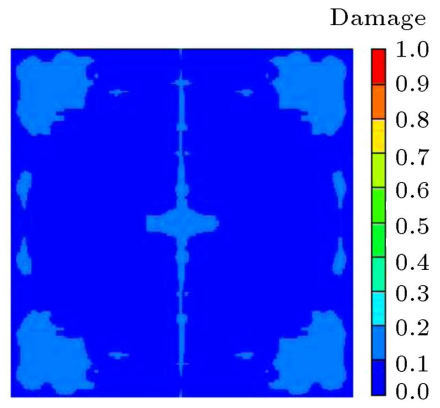

(b) Top face (FE-analysis)

Damage

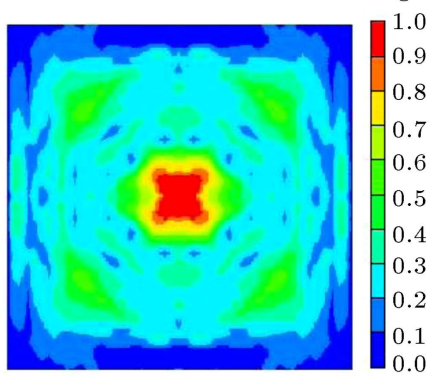

(d) Bottom face (FE-analysis)
Figure 11. Comparisons of numerical and experimental [26] damage patterns occurred in test NRC-1.

center of the slab. The damage pattern on the bottom surface of the slab includes spalling of concrete cover over a radius of approximately $85 \mathrm{~mm}$ at the center of the slab together with longitudinal and curvilinear cracks (Figure 12(c)). The spalling area in the FE analysis acquires a radius of $75 \mathrm{~mm}$ that is less than $12 \%$ and smaller than the experimental observation. Although a significantly large area of the slab is shown to be damaged, the longitudinal cracks are not visible 


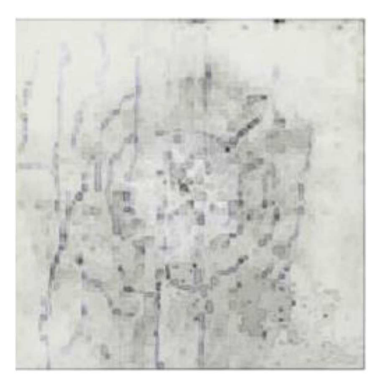

(a) Top face (experiment)

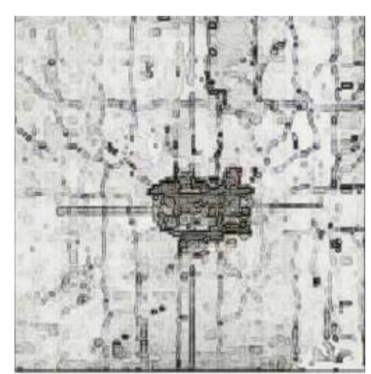

(c) Bottom face (experiment)

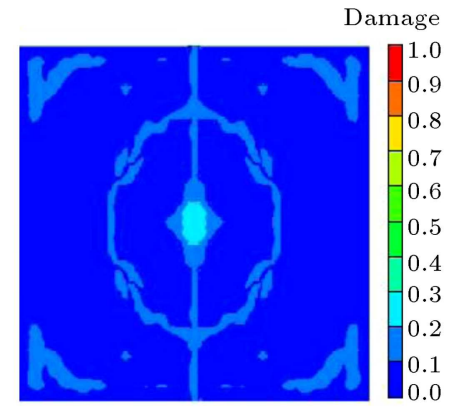

(b) Top face (FE-analysis)

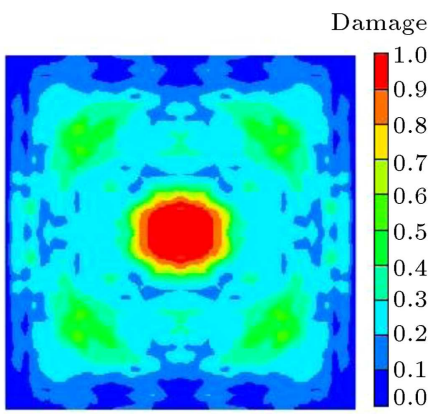

(d) Bottom face (FE-analysis)
Figure 12. Comparisons of numerical and experimental [26] damage patterns occurred in test NRC-2.

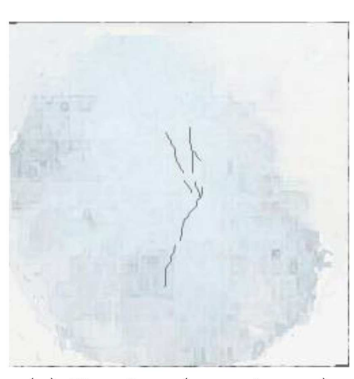

(a) Top face (experiment)

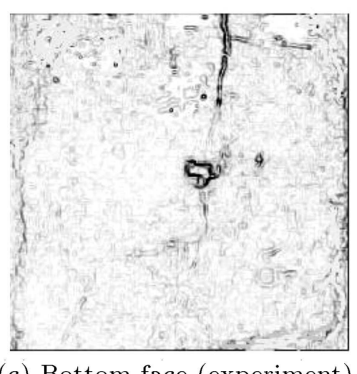

(c) Bottom face (experiment)

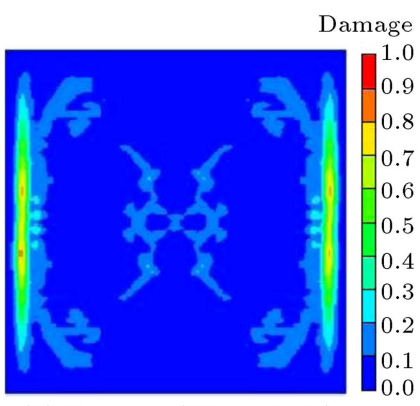

(b) Top face (FE-analysis)

Damage

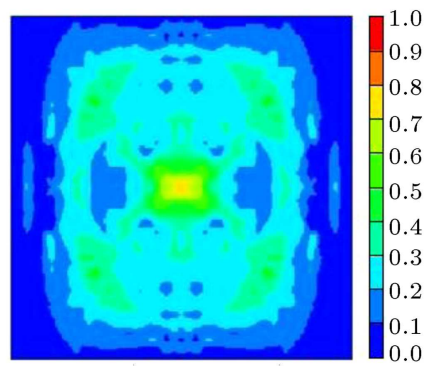

(d) Bottom face (FE-analysis)
Figure 13. Comparisons of numerical and experimental [5] damage patterns occurred in test NRC-3.

in the FE model. These relatively undermined damages occur because the blast-overpressure is slightly underestimated in the FE analysis, as compared to their status in reality.

Figure 13 includes the damages occurred in test NRC-3. As seen in Figure 13(a), overall, the level of

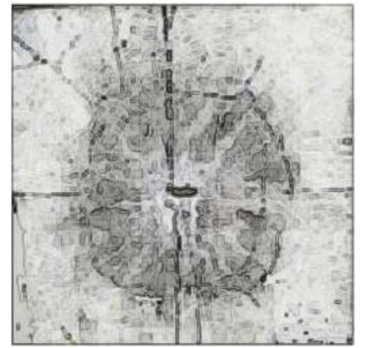

(a) Top face (experiment)

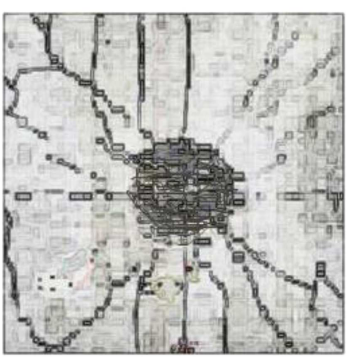

(c) Bottom face (experiment)

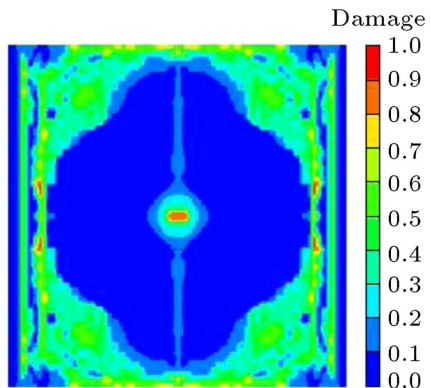

(b) Top face (FE-analysis)

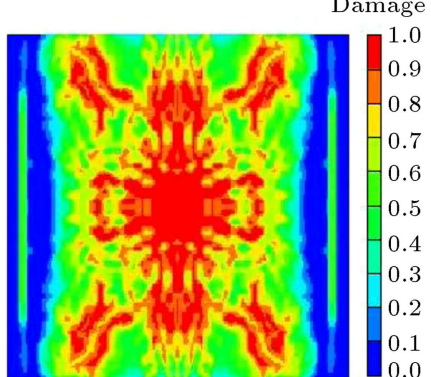

(d) Bottom face (FE-analysis)
Figure 14. Comparisons of numerical and experimental [26] damage patterns occurred in test NRC-4.

damage on the top surface is negligible. The minor cracks at the central region of the slab have been well simulated by the FE analysis (Figure 13(b)). However, due to fully rigid boundary conditions defined in the FE model, the supported edges of the slab have experienced further damage, as compared to the experimental observation. According to Figure 13(c), the damage pattern on the bottom face of the slab is composed of minor spalling of concrete cover at the center together with a longitudinal crack of approximately $5 \mathrm{~mm}$ width, partially developed at the mid span. The FE analysis predicts the damaged area at the center of the slab.

Figure 14(a) contains the damages occurred on the top face of the slab in test NRC-4. Due to the significant flexural deformations that occurred under the relatively massive explosion, a small portion of the concrete cover has been broken up at the center of the slab. A similar damage pattern can be obtained from the FE analysis. As seen in Figure 14(b), the FE analysis simulates the central damaged area as well as the longitudinal crack at the mid span of the slab specimen. The circular cracks are formed around the center of the slab at a relatively greater radius, in comparison to the experimental observation.

Figure 14(c) indicates the damage pattern on the bottom surface of the slab in the experimental study [22]. The damage characteristics include significant spalling of concrete cover (at a radius of approximately $120 \mathrm{~mm}$ ) and a number of cracks that propagate outward from the center of the slab. The FE model simulates the damaged area at the center of the slab (at a radius of approximately $110 \mathrm{~mm}$ ) as well 
Table 6. Comparison of the Finite-Element (FE) and experimental studies.

\begin{tabular}{|c|c|c|c|c|c|c|c|}
\hline \multirow[b]{2}{*}{ Test } & \multirow[b]{2}{*}{$\begin{array}{c}\text { Slab } \\
\text { name }\end{array}$} & \multicolumn{2}{|c|}{$\begin{array}{l}\text { FE analysis results } \\
\text { using Kinney and Graham [16] } \\
\text { empirical relations }\end{array}$} & \multicolumn{2}{|c|}{$\begin{array}{c}\text { Experimental results } \\
\qquad[5,26]\end{array}$} & \multicolumn{2}{|c|}{$\begin{array}{c}\text { Error in numerical } \\
\text { analysis }\end{array}$} \\
\hline & & $\begin{array}{c}\text { Central } \\
\text { deflection, } \delta \\
(\mathrm{mm})\end{array}$ & $\begin{array}{l}\text { Spall radius } \\
\quad(\mathrm{mm})\end{array}$ & $\begin{array}{c}\text { Central } \\
\text { deflection, } \delta \\
(\mathrm{mm})\end{array}$ & $\begin{array}{c}\text { Spall } \\
\text { radius } \\
(\mathrm{mm})\end{array}$ & $\begin{array}{c}\text { Central } \\
\text { deflection, } \delta \\
(\mathrm{mm})\end{array}$ & $\begin{array}{l}\text { Spall } \\
\text { radius } \\
(\mathrm{mm})\end{array}$ \\
\hline NRC-1 & $\mathrm{A}$ & 8.48 & 45 & 9 & 50 & $-5.8 \%$ & $-10 \%$ \\
\hline NRC-2 & A & 23.43 & 75 & 26 & 85 & $-9.9 \%$ & $-11.8 \%$ \\
\hline NRC-3 & B & 9.28 & $\mathrm{~N} / \mathrm{A}$ & 10 & $\mathrm{~N} / \mathrm{A}$ & $-7.2 \%$ & $\mathrm{~N} / \mathrm{A}$ \\
\hline NRC-4 & $\mathrm{C}$ & 17.33 & 110 & 19 & 120 & $-8.8 \%$ & $-8.3 \%$ \\
\hline
\end{tabular}

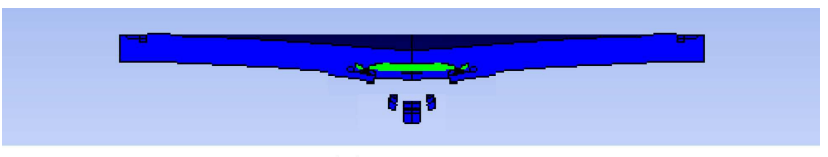

(a) Test NRC-1

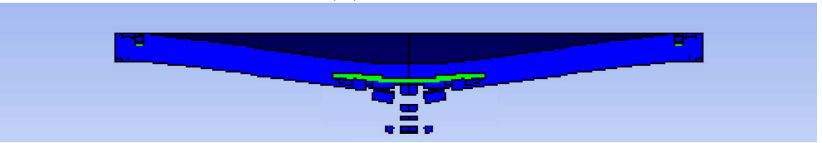

(b) Test NRC-2

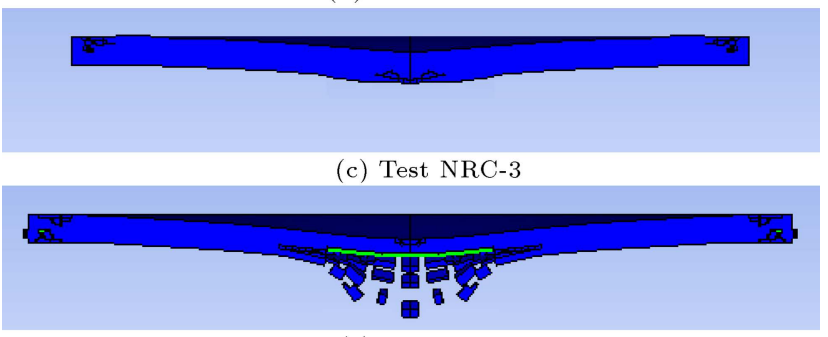

(d) Test NRC-4

Figure 15. Cross-section of the deformed and damaged concrete slabs in tests NRC-1 to NRC-4.

as the outward propagation of flexural cracks on the center of the bottom face of slab specimen. The smaller damage area is likely associated with the fact that the blast-overpressure in the FE analysis is relatively underestimated. An interesting feature of comparison is the formation of flexural cracks that are originated from the center and propagate toward the corners of the slab. These diagonal cracks are observed in both of the experimental (Figure 14(c)) and FE analysis (Figure 14(d)) studies. The FE analysis shows the formation of cracks close to the supported edges of the slab. It is postulated that, during the testing program, the rotational boundary condition of the slab at its supports has not been fully restrained as opposed to the FE modeling.

Figure 15(a) to (d) show the cross-section of concrete slabs NRC-1 to $\mathrm{NRC}-4$, respectively, after the explosions. As observed, the vertical deflection of the slabs and the spalling regions of concrete are simulated in the FE model proposed in this paper. The permanent deformation at the center of the slab and the radius of concrete spalling region are shown in Table 6.

Table 6 compares the numerical and experimental magnitudes of peak deflection and the spall radius occurred at the center of slab specimens. According to the data cited in this table, the error in the prediction of deflections is less than $11 \%$. The spall radius on the bottom surface of the slab specimens has been simulated with less than $12 \%$ error. These levels of accuracy are sufficient for many practical applications. Furthermore, a close examination of Figures 11-14 suggests that, in general, reasonable agreement exists between the damage pattern observed in the experimental studies and the results of $\mathrm{FE}$ analysis for tests NRC-1 to NRC-4. As such, the performance of Kinney and Graham [16] model in the prediction of peak overpressure and time duration of blast load for the scaled distances of less than $3 \mathrm{~m} / \mathrm{kg}^{1 / 3}$ (the focus of this paper) is deemed satisfactory.

When comparing the results of FE analysis with those of experimental studies, one should note that, in addition to the peak-magnitude and time duration of blast-overpressure Kinney and Graham [16], a number of other factors influence the accuracy of analysis. These additional factors include the magnitude of ambient pressure, the time decay model used for blast peak overpressure, constitutive models employed for concrete and steel materials, size of finiteelement mesh, and the boundary conditions of slab specimens.

\section{Conclusions}

The effective simulation of blast overpressure is a key requirement for response analysis or design of structures that are subjected to explosive incidents. The design calculation in such cases involves the use of one or a number of empirical models that are employed to simulate the peak magnitude and time duration of blast overpressure on the basis of the mass of explosive material (or the charge weight, $W$ ) and its standoff 
distance, $R$, from the structure. In blast engineering, these two parameters are typically combined in a single parameter called "scaled distance", which is defined as $Z=R / W^{1 / 3}$. A relatively large inventory of models to simulate the blast loading effects currently exists in the literature. However, the outcomes of these models may be widely dispersed for a given structure and a given $Z$. The main objective of this paper was to examine the effectiveness of various empirical models in simulating the blast load on structures that were subjected to the explosions with $Z \leq 3 \mathrm{~m} / \mathrm{kg}^{1 / 3}$. To achieve the research objectives, the blast responses of eight various concrete slabs were investigated numerically using Finite-Element (FE) analysis. A simplified approach was developed to simulate the nonlinear distribution of blast overpressure across the concrete slabs. The results of $\mathrm{FE}$ analysis runs, including the peak central deflection of the slabs, and the pattern of damages induced on the top and bottom faces of the slabs were evaluated and, then, compared with previous experimental results available in the literature. Given the range of 0.5 to $3.0 \mathrm{~m} / \mathrm{kg}^{1 / 3}$ of $Z$ values as the focus of this paper, the main conclusions of this research study are as follows:

- The time duration of overpressure phase of explosion can be effectively estimated using the empirical models developed by Kinney and Graham [16] as well as Brode [11]. Kinney and Graham [16] model was found to be more accurate than that of Brode [11] model;

- The time duration evaluated by Kinney and Graham [16] provided a lower bound to the other empirical models studied in this paper;

- The use of Kinney and Graham [16] time duration in conjunction with the peak overpressure evaluated by the other empirical models significantly improved the effectiveness of the empirical models in blast load simulation;

- The simplified approach developed in this paper was found to be effective in simulating the nonuniform distribution of blast overpressure across the concrete slabs;

- The magnitudes of error in the evaluation of peak central deflection of the slabs were minimal (less than $10 \%$ ) when both the peak magnitude and time duration of overpressure were evaluated by the pair of empirical equations developed by Kinney and Graham [16];

- In general, all of the empirical models, excluding Kinney and Graham [16] model, overestimated the blast-impact (area under time-overpressure curve) for the concrete slabs studied in this paper;

- Among all of the empirical models investigated in this paper, the empirical equations developed by
Kinney and Graham [16] were found to be efficient in the evaluation of peak magnitude and time duration of blast overpressure phase when scaled distance $Z$ was less than $3 \mathrm{~m} / \mathrm{kg}^{1 / 3}$;

- Overall, good agreement was found between the $\mathrm{FE}$ analysis results and the experimental studies in terms of the damage pattern including the radius of spalling area of concrete cover on the back of the slabs and the orientation of cracks formed on both sides of the slabs.

\section{Acknowledgement}

The authors are grateful to the student fellowship granted by Razi University to the first author of this paper.

\section{References}

1. Chang, J.I. and Lin, C.C. "A study of storage tank accidents", Loss Prevention in the Process Industries, 19(1), pp. 51-59 (2006).

2. Zhou, X.Q., Kuznetsov, V.A., Hao, H., and Waschl, J. "Numerical prediction of concrete slab response to blast loading", Int. J. Impact. Eng., 35, pp. 1188-1200 (2008).

3. Tai, Y.S., Chu, T.L., Hu, H.T., and Wu, J.Y. "Dynamic response of a reinforced concrete slab subjected to air blast load", Theor. Appl. Fract. Mec., 56, pp. 140-147 (2011).

4. Zhao, C.F. and Chen, J.Y. "Damage mechanism and mode of square reinforced concrete slab subjected to blast loading", Theor. Appl. Fract. Mec., 63-64, pp. 54-62 (2013).

5. Wang, W., Zhang, D., Lu, F., Wang, S., and Tang, F. "Experimental study and numerical simulation of the damage mode of a square reinforced concrete slab under close-in explosion", Eng. Fail. Anal., 27, pp. 4151 (2013).

6. Li, J. and Hao, H. "Numerical study of concrete spall damage to blast loads", Int. J. Impact. Eng., 68, pp. 41-55 (2014).

7. Koneshwaran, S., Thambiratnam, D.P., and Gallage, C. "Response of segmented bored transit tunnels to surface blast", Adv. Eng. Softw., 89, pp. 77-89 (2015).

8. UFC 3-340-02 "Structures to resist the effects of accidental explosions", Unified Facilities Criteria, US Department of Defense, Washington DC (2009).

9. Mays, G.C. and Smith, P.D., Blast Effects on Buildings, Thomas Telford Services Ltd, 1 Heron Quay, London (1995).

10. Flynn, P.D. "Elastic response of simple structures to pulse loading", Ballistics Research Laboratory, Aberdeen Proving Ground, Maryland, USA, BRl Memo Report No. 525 (1950). 
11. Brode, H.L. "Numerical solutions of spherical blast waves", J. App. Phys., 26(6), pp. 766-775 (1955).

12. Ethridge, N.M. "Blast effects on simple objects and military vehicles II operation SUN BEAM", US Army Armament Research and Development Center, Ballistics Research laboratory, Aberdeen Proving Ground, Maryland, USA, Project 1.3, POR-2261 (1964).

13. Dewe, J.M. "The air velocity in blast waves from T.N.T. explosions", Proc. Roy. Soc. Lond., A 279(1378), pp. 366-385 (1964).

14. Friedlander, F.G. "The diffraction of sound pulses. I. Diffraction by a semi-infinite plate", Proc. Roy. Soc. Lond., A 186(1006), pp. 322-344 (1946).

15. Baker, W., Explosions in Air, University of Texas Press, Austin, USA (1973).

16. Kinney, G.F. and Graham K.J., Explosive Shocks in Air, Springer, Berlin (1985).

17. Rankine, W.J.M. "On the thermodynamic theory of waves of finite longitudinal disturbance", Phil. Trans. Roy. Soc. Lond., 160, pp. 287-288 (1870).

18. Henrych, J., The Dynamics of Explosion and Its Use, Elsevier, Amsterdam (1979).

19. Sadovskiy, M.A. "Mechanical effects of air shock waves from explosions according to experiments", in: M.A. Sadovskiy Selected Works: Geophysics and Physics of Explosion, Nauka press, Moscow (2004).

20. Michael, M. and Swisdak, J.R., Simplified Kingery Air Blast Calculations, Naval Surface Warfare Center, Indian Head Division (1994).

21. Wu, C., Oehlersa, D.J. Rebentrostb, M. Leachc, J., and Whittakerd, A.S. "Blast testing of ultra-high performance fiber and FRP-retrofitted concrete slabs", Eng. Struct., 31, pp. 2060-2069 (2009).

22. Wang, W., Zhang, D., Lu, F., Wang, S., and Tang, F. "Experimental study on scaling the explosion resistance of a one-way square reinforced concrete slab under a close-in blast loading", Int. J. Impact. Eng., 49, pp. 158-164 (2012).

23. AUTODYN, Theory Manual, Century Dynamics (2006).

24. LS-DYNA V971, Keyword Manual, 1 and 2. Livermore, CA: Livermore Software Technology Corporations (2009).

25. Thiagarajan, G., Kadambi, A.V., Robert, S., and Johnson, C.F. "Experimental and finite element analysis of doubly reinforced concrete slabs subjected to blast loads", Int. J. Impact. Eng., 75, pp. 162-173 (2015).

26. Riedel, W., Thoma, K., and Hiermaier, S. "Numerical analysis using a new macroscopic concrete model for hydro codes", In Proc. of 9th International Symposium on Interaction of the Effects of Munitions with Structures, Berlin, Germany, pp. 315-322 (1999).
27. Herrmann, W. "Constitutive equation for the dynamic compaction of ductile porous materials", J. Appl. Phys., 40, pp. 2490-2499 (1969).

28. Tu, Z.G. and Lu, Y. "Evaluation of typical concrete material models used in hydro codes for high dynamic response simulations", Int. J. Impact. Eng., 36(1), pp. 132-146 (2009).

29. Johnson, G.R. and Cook, W.H. "A constitutive model and data for metals subjected to large strains, high strain rates and high temperatures", In Proc. of the Seventh International Symposium on Ballistics, Hague, Netherlands, pp. 541-548 (1983).

30. Newmark, N.M. and Hansen, R.J. "Design of blast resistant structures", Shock and Vibration Handbook, 3, Harris and Crede, Eds. McGraw-Hill, New York, USA (1961).

31. Held, M. "Blast waves in free air", Propellants, Explosives, Pyrotechnics, 8(1), pp. 1-8 (1983).

32. Mills, C.A. "The design of concrete structure to resist explosions and weapon effects", In Proc. the 1st Int. Conference on Concrete for Hazard Protections, Edinburgh, UK, pp. 61-73 (1987).

33. Bajić, Z. "Determination of TNT equivalent for various explosives", Master's Thesis, University of Belgrade, Belgrade (2007).

\section{Biographies}

Alireza Rasooli is currently a Research Engineer at Larze Badal Kar (LBK), a science-oriented company that is active in the field of structural engineering. He is an expert in blast analysis and design of structures. He received his MSc in Civil Engineering, Structures, from Razi University, Iran in 2015, where he had completed his BSc in Civil Engineering in 2012.

Hamid Toopchi-Nezhad is currently an Assistant Professor at the Department of Civil Engineering at Razi University Kermanshah, Iran. His teaching expertise and main research area include vibration analysis and control of structures. He has been the supervisor of around 20 graduate students. Dr. Toopchi-Nezhad is the founder of a science-oriented company that is active in seismic retrofitting and vibration control of structures. He is the holder of an Innovator Distinction Award granted by McMaster University in 2016. He is the recipient of a postdoctoral fellowship awarded by the Ministry of Research and Innovation of Ontario, Canada (2009 to 2011). He completed his PhD in Structural Engineering within the Department of Civil Engineering at McMaster University, Canada, in Dec. 2008. His research focused on experimental simulation and numerical modeling of a base isolated structure utilizing novel fiber reinforced elastomeric seismic isolators. He designed and fabricated a fully automatic and programmable servo-hydraulic testing apparatus at 
the Applied Dynamic Laboratory (ADL) of McMaster University for his experimental research program. He is a recipient of the Kasimir Gizawski Medal awarded by the Canadian Society of Civil Engineers for one of his journal papers published in 2009. He held a Lecturer position in Civil Engineering at Razi University, Iran, for 7 years prior to enrolling at McMaster University in Sept. 2004. He received his MS degree in Structural Engineering from Shiraz University, Shiraz, Iran, in 1996. He completed his BS in Civil Engineering from AmirKabir University of Technology, Tehran, Iran in 1993. 